\title{
Caster Semenya, athlete classification, and fair equality of opportunity in sport
}

\author{
Sigmund Loland
}

Department of Sport and Social Sciences, The Norwegian School of Sport Sciences, Oslo, Norway

\section{Correspondence to}

Professor Sigmund Loland, Department of Sport and Social Sciences, The Norwegian School of Sport Sciences, Oslo 0860, Norway; sigmund.loland@nih.no

Received 4 November 2019 Revised 18 February 2020 Accepted 3 March 2020 Published Online First 20 July 2020

\section{Linked}

- http://dx.doi.org/10.1136/ medethics-2020-106506 - http://dx.doi.org/10.1136/ medethics-2020-106508 - http://dx.doi.org/10.1136/ medethics-2020-106509

- http://dx.doi.org/10.1136/ medethics-2020-106748

- http://dx.doi.org/10.1136/ medethics-2020-106755

\section{Check for updates}

(C) Author(s) (or their employer(s)) 2020. No commercial re-use. See rights and permissions. Published by BMJ.

To cite: Loland S.
$\mathrm{J}$ Med Ethics

2020:46:584-590

\section{ABSTRACT}

According to the Differences of Sex Development (DSD) Regulations of the International Association of Athletics Federations (IAAF), Caster Semenya and other athletes with heightened testosterone levels are considered noneligible for middle distance running races in the women's class. Based on an analysis of fair equality of opportunity in sport, I take a critical look at the Semenya case and at IAAF's DSD Regulations. I distinguish between what I call stable and dynamic inequalities between athletes. Stable inequalities are those that athletes cannot impact or control in any significant way such as inequalities in biological sex, body size and chronological age. Dynamic inequalities, such as inequalities in strength, speed and endurance, or in technical and tactical skills, can be impacted and to a certain extent controlled by athletes. If stable inequalities exert significant and systematic impact on performance, they provide a rationale for classification. If high testosterone level is an inborn, strong and systemic driver of performance development, inequalities in such levels can provide a rationale for classification. As is emphasised by the Court of Arbitration for Sport (CAS), this leads to a dilemma of rights: the right of Semenya to compete in sport according to her legal sex and gender identity, and the right of other athletes within the average female testosterone range to compete under fair conditions. I conclude with providing conditional support of the CAS decision in the Semenya case and of IAAF's DSD Regulations.

\section{INTRODUCTION}

Over the last decade, the eligibility of South African athlete Caster Semenya for competition in women's middle distance running has caused a series of controversies culminating at the end of July 2019 with her suspension by the International Association of Athletics Federations (IAAF). In what follows, I will critically examine the main arguments pro and contra Semenya's eligibility and IAAF's Differences of Sexual Development (DSD) Regulations. In a recent comment, Camporesi notes that the discourse has been dominated by disagreements on how to interpret empirical data on testosterone levels and performance advantage, and not the underlying normative assumptions on gender and fairness. ${ }^{1}$ I will attempt to fill some of this gap in the literature. More specifically, and based on what I take to be the normative rationale for athlete classification, I will provide conditional support of the IAAF position.

\section{THE SEMENYA CASE}

Discussions about Semenya's eligibility in the women's class arouse primarily after her success in the 2009 IAAF World Championships in Athletics in Berlin. The IAAF abandoned universal sex verification tests in 1992 but has the possibility of testing when eligibility is questioned of a women's class competitor. Hence, Semenya had to submit to eligibility tests. ${ }^{2}$ Having an assumed hyperandrogenism condition, an intersex condition leading the body to naturally produce androgens (among them testosterone) at significantly higher levels than in average women, Semenya was considered by the IAAF to have an unfair competitive advantage.

In 2011, the IAAF introduced Hyperandrogenism Regulations that put a cap on athletes' testosterone levels in the women's class. In 2015, after a challenge by the Indian athlete Dutee Chand on lack of scientific evidence for correlations between endogenous testosterone and performance advantage, the Court of Arbitration for Sport (CAS) delivered an interim report with partial support of Chand and a call for a temporary regulation suspension. ${ }^{\mathrm{i}}$ IAAF was given 2 years to provide evidence and further justification of their rules.

In April 2018, the IAAF introduced the DSD Regulations to come into force of 1 November $2018 .^{4}$ ii The rules were made valid only for individuals with 46 XY DSD conditions (a chromosome pattern normally found in males as compared with the normal female XX pattern), with testosterone levels above $5 \mathrm{nmol} / \mathrm{L}$ blood, and who experience a 'material androgenising effect'. ${ }^{6}$ Moreover, the rules applied only to 'certain events', that is, to middle distance running distances from $400 \mathrm{~m}$ to one English Mile. To compete in the women's class, athletes with testosterone levels above the defined threshold were required to lower their levels and stay below for at least 6 months. In practical terms, for athletes concerned this meant undergoing suppressive testosterone therapy.

On 30 April 2019, CAS dismissed a request for arbitration, this time submitted by Semenya. With a 2-1 vote, the three judges ruled that discrimination as defined in the IAAF DSD Regulations was '... a necessary, reasonable and proportionate means of achieving the legitimate objective of ensuring fair competition in female athletics in certain events and protecting the "protected class" of female athletes in those events'. At the end of July 2019, and after a temporary suspension by the Swiss Supreme Court, ${ }^{8}$ the DSD Regulations were put into practice.

The main IAAF argument is that of a level playing field and of protecting the integrity of the women's class. Although enhanced testosterone

\footnotetext{
${ }^{\mathrm{i}}$ My summary of the case is based on CAS's Executive Summary of the Semenya case.

${ }^{i i}$ For details, see IAAF's Eligibility Regulations for
} the Female Classification. ${ }^{5}$ 
levels due to hyperandrogenism is a 'natural' state (and not an outcome of medical intervention or manipulation), it is still considered a source of unfair competition. Typically, in healthy men testosterone levels range from 7.7 to $29.4 \mathrm{nmol} / \mathrm{L}$, whereas the levels in healthy women range from 0.12 to $1.7 \mathrm{nmol} / \mathrm{L} .{ }^{9}$ Statistically, healthy men have $15-20$-fold higher testosterone levels than their female counterparts. There is solid scientific support of the view that increased testosterone levels can enhance most athletic performances in terms of basic biomotor capabilities such as strength, speed and endurance. Although more controversial, there is also scientific support of $5 \mathrm{nmol} / \mathrm{L}$ as a reasonable maximum threshold in the women's class. ${ }^{10}$

Still, the DSD Regulations are exposed to stern criticism from several perspectives. ${ }^{11-13}$ iii Arguments from Semenya and her team of lawyers sum up much of the criticism. The setting of thresholds is problematic and even arbitrary from a scientific point of view, the regulations build on essentialist and reductionist definitions of gender, they imply a violation against human rights, they lead to unfair discrimination and the required suppressive testosterone therapy can impose significant harm on the athletes affected. ${ }^{15}$

In their ruling, CAS acknowledges the critique and point to the Semenya case as involving incomparable, competing rights: the right of athletes to compete in sport without being discriminated based on their legal sex and gender identity, and the right of female athletes without DSD conditions to compete in sport and enjoy fair competition.

What is the ethically right solution in this situation?

In their 2011 regulations, IAAF emphasised that measuring athletes' androgen levels is not to be seen as part of a 'gender policy' or a 'gender verification' procedure but as a quest for fairness. ${ }^{16}$ Still, as Gleaves and Lehrbach note, the Semenya discourse is interwoven in extensive social and cultural narratives of gender. ${ }^{17}$ Even more, Semenya's case raises general questions on classification of sport competitors and goes straight to the heart of the normative structure and meaning of sport. ${ }^{18}$

\section{CLASSIFICATION IN SPORT}

The most common classification schemes in sport are related to age, biological sex and body size. Let me give some examples.

Almost all sports have classes for children, youth, adults and master or senior athletes. Age classes differ between sports related to the impact of age on performance. For example, in national elite championships, the Fédération Internationale de Football Association (FIFA) advices classifying players in 2-year intervals: U (under)-13, U-15, U-17, U-19 and U-21. ${ }^{19}$ Soccer is a demanding sport in terms of biomotor capabilities (strength, speed and endurance) which depends on biological development and age. In sailing on the other hand, age classes are less fixed. The sport requires significant technical and tactical insights and skills, but is less demanding when it comes to biomotor capabilities. The World Sailing Classification Code includes a rather complex scheme, for instance with classification of athletes between 18 and 22 years of age and with limited experience together with athletes above 70 years of age. ${ }^{20}$

Similarly, most sports operate with sex classification, that is, with girls' and boys' and women's and men's classes. The history

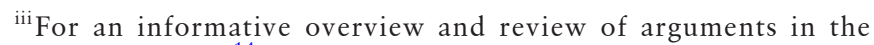
debate, see Ref. ${ }^{14}$ of sex classification and sex verification in sport is a long and troubled one including visual inspection and simplistic chromosome testing with little regard for athletes' legal sex and gender identity. ${ }^{21}$ Controversies over successful female athletes having visual characteristics of men, such as well-defined muscles, broad shoulders, small breasts and narrow hips, are fuelled by prejudice and sexist attitudes. ${ }^{22}$

Still, sex segregation in sport seems to be generally accepted, in particular in sports where there seem to be clear differences in performance potential between men and women. ${ }^{\text {iv }}$ Statistically, for instance, in sex segregated running events in athletics, there is a $10 \%-12 \%$ performance difference. ${ }^{24}$ Other examples include weight lifting, swimming or team games such as rugby. As with age, classification according to sex has less relevance in more complex events where tactical disposition and finer motor skills are decisive for the outcome such as equestrian events, shooting and sailing.

A third classification category is that of body weight. Obviously, in events such as weight lifting and combat sports in which body weight exerts significant impact, classification is called for. ${ }^{v} \mathrm{~A}$ forth category is classification between able and disabled athletes and between Olympic and Paralympic events within which further classifications are made, for instance in age and sex. vi, vii $^{2}$

The above classification accounts are descriptive rather than normative. They offer frameworks for reasoning but not really solutions in dilemmas such as in the Semenya case and in assessment of IAAF's DSD Regulations. Premises for classification have to be scrutinised from a critical, normative point of view. Do the regulations have a sound ethical rationale? What, more precisely, are the norms on which classification schemes are based?

\section{FAIR EQUALITY OF OPPORTUNITY}

The CAS ruling points to a basic rationale of classification: to secure fair competition and equality of opportunity (EO). In sport, $\mathrm{EO}$ is a means to enable evaluations of a particular kind of human inequality, or, more precisely, to enable measuring, comparing and ranking of competitors according to athletic performances as defined in the rules of each sport. ${ }^{27}$ In soccer,

\footnotetext{
${ }^{\text {iv }}$ By and large, the International Olympic Committee (IOC) supports IAAF's classification systems and DSD policy. ${ }^{23}$

${ }^{\mathrm{v}}$ The main argument for body size classification in combat sport is linked to fairness and meaningful competition. Moreover, in full contact sports such as Mixed Martial Arts, uneven matching and classification can cause physical harm. See, for example, the heated debate over the transsexual athlete Fallon Fox. ${ }^{25}$

${ }^{\text {vi }}$ Controversies over classification concern not only biological sex. Biotechnological innovations challenge the distinction between Olympic and Paralympic athletes. South African track and field-athlete Oskar Pistorius is a paradigmatic case. Being an amputee, his prosthetic limbs enabled him to run the $400 \mathrm{~m}$ with results qualifying for Olympic competition. During the 2012 London Games, Pistorius became the first visibly disabled athlete to compete in the Olympics. Similar to the case of Semenya, his eligibility caused controversies involving IAAF, IOC and CAS. ${ }^{26}$

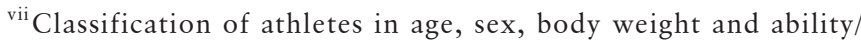
disability is often referred to as selective classification. Another classification scheme is the more dynamic one of performance levels. Athletes and teams are considered eligible or ineligible for events, leagues, cups and series based on quality of performance. Football clubs qualify for European Champions League based on results, javelin throwers are eligible for an Olympic final based on the length of their throws in the qualifying rounds. Performance classification, however, is based on evaluations within selective classification schemes and will not be further discussed here.
} 
teams aim at scoring more goals than their opponents. In running races in athletics, the aim is to break the finishing line first. Still, despite a diversity of sport-defined capabilities and skills, athletic performances seem to share some common characteristics.

Most conceptions involve an emphasis on bodily movements and skills. ${ }^{28}$ Athletic performances depend on genetic predispositions for developing basic biomotor capabilities of strength, speed and endurance, and for technical and tactical skills including mental qualities. These performance phenotypes are outcomes of a high number of interplaying factors from the chance event of conception and formation of a unique genetic makeup in the so-called 'natural lottery', via numerous genegene-environment interactions in the physical, psychological, social and cultural contexts in which athletes find themselves, and all the way up to situational factors (a sudden gust of wind, a comment from a competitor, an acute injury) at the moment of performance. Each athletic performance is unique and 'authentic' in the sense of being an expression of one particular individual's life-long developmental history.

In sport, some of these factors are highlighted and considered relevant whereas others are attempted eliminated or at least compensated for. Just as every sport has a definition of what counts as valid performance, every sport has rules defining what count as non-relevant and confounding factors. There is diversity here as well. One and the same action can be banned in one sport and cultivated in another. Intentional punches to the face are penalised in most sports, but celebrated in boxing. The question now is whether there are more general norms underlying definitions of non-relevant factors, and, more specifically, whether these norms can illuminate the classification rationale.

Main classification categories such as biological sex, and body size refer to inequalities that are closely linked to genetic predispositions. Other aspects of genetically given talent do not seem to provide similar classification concerns. Some athletes have a talent for developing strength and speed; others have a talent for endurance sports. Some adapt easily to hard training and are resistant when it comes to injuries; others are more easily overtrained and injured. These are all inequalities that count in performance evaluations. Why is this the case?

Few sporting bodies offer an explicit rationale for their classification schemes. One exception is the International Paralympic Committee (IPC). In a position statement on classification, the IPC provides interesting clues:

\begin{abstract}
Classification in sport reduces the likelihood of one-sided competition and in this way promotes participation... Paralympic sports require selective classification systems so that athletes who enhance their competitive performance through effective training will not be moved to a class with athletes who have less activity limitation, as they would in a performance classification system. ${ }^{29}$
\end{abstract}

Similar aspects are emphasised from the International Committee for Fair Play in pointing to the responsibility of sport organisations to organise competitions between competitors of similar size, power and capacities. ${ }^{30}$ During the Semenya controversy, and after a June 2019 meeting with Athletics South Africa President Aleck Skhosana, IAAF President Sebastian Coe provided an even clearer argument. The DSD Regulations were intended to meet the

... need to create competition categories within our sport that ensures that success is determined by talent, dedication and hard work, rather than by other factors that are not considered fair or meaningful, such as the enormous physical advantages that an adult has over a child, or a male athlete has over a female athlete. ${ }^{31}$
This resonates well with a more general ethical ideal of EO. In its formal and general version, EO prescribes that '... positions and posts that confer superior advantages are open to all applicants'. ${ }^{32}$ This formal version however does not provide concrete solutions in dilemma situations. Elster has shown how different social and political institutions and practices have different goals and corresponding schemes of distributive justice. ${ }^{33}$ A commercial company may have as its main goal to maximise profit. When hiring a new person, EO requires open announcement and a strict application of the criteria of maximising profit abilities. If the company operates in a racist market in which people of colour are looked down on, there would be no hiring of coloured people as they would have a disadvantage in their market operations. In a similar vein, a professional track and field team may have as its main goal to hire the fastest runners. Positions are announced openly, and athletes are hired based on their actual and potential performance potential. Statistically speaking, men's performances are 10\%-12\% faster than those of their female counterparts. In a non-segregated sport system, the team would hire men only.

Most people would find these procedures problematic. There are additional norms and values at play here. EO needs to be substantiated. Rawls points to the ideal of fair equality of opportunity (FEO) prescribing that individuals with similar endowments and talents and similar ambitions should be given similar opportunities and roughly equivalent prospects for competitive success. ${ }^{34}$ In most matters of distributive justice, inequalities in factors such as age, biological sex, ethnic and religious background, colour of skin, or sexual orientation are considered arbitrary and non-relevant. These are all inequalities in what we may call stable background variables that individuals cannot control or impact in any significant way. They are matters of luck (good and bad). ${ }^{\text {viii }}$ FEO, then, is an expression of what Anderson labelled 'luck egalitarianism'. ${ }^{35}$

As a general norm regulating the distribution of diverse goods and burdens in society, the luck egalitarian version of FEO is controversial. ${ }^{36}$ In the far more limited context of a sport competition, the structural goal is clear: to measure, compare and rank competitors according to rule-defined athletic performance. Inequalities in strength, speed and endurance, and in technical and tactical skills are dynamic in the sense that they can be developed and cultivated by hard work and effort on the athlete side. Dynamic inequalities are considered relevant. Stable inequalities in chronological age, sex, body size and disability/ability on the other hand are considered non-relevant. When it comes to most positions and posts in society, stable inequalities do not exert significant impact on performance outcomes. Theoretically (but not necessarily in real life as, in most societies, there is an ongoing proactive struggle against prejudice and unjust discrimination), their impact can be eliminated simply by disregarding them. In many sports, however, stable inequalities between athletes in for instance biological sex and body size do exert impact, sometimes significantly so. Elimination by disregarding them is impossible, and the operative option is classification. Here, too, however, FEO is the backing norm.

\footnotetext{
viii Being a 'stable' inequality does not indicate that there can be no development or change. Age, for one, is in constant change. The discussion here, however, concerns chronological age as this is the foundation for age classification. Chronological age inequalities can be labelled stable as they are outside of individual control and impact, and they proceed universally and in identical ways. Inequalities in religious background and sexual preference can change, too, but in general such changes are rare. Hence, referring to these inequalities as stable makes sense.
} 
Luck egalitarian FEO concerns not only classification schemes but is followed in the set-up of sport in many ways and is a core element of sport's normative structure. One obvious example is requirement on equal external conditions. In running races, everyone runs the same distance on the same surface and are timed with the same technology. In team sports, teams shift sides between periods of play to even out potential inequalities in surface, light, spectator influence, and (in outdoor sports) climatic conditions. A second area relates to sport equipment and technology. Without reasonably strict standardisation of sailing boats, technical and tactical skills of sailing would be difficult to evaluate. Without standardised javelins, shots and sledge hammers, throwing events in athletics would make little sense. A third application area (and the topic of this essay) deals with individual inequalities between athletes such as inequalities in biological sex.

Before returning the Semenya case and sex classification, a further question should be addressed. Why should a luck egalitarian FEO norm be followed in sport? What, more fundamentally, is the rationale or the values behind by this norm?

One incentive for classification is found in the history of sport gambling and the quest for even contests and open outcomes. ${ }^{37}$ In an era of entertainment sport, there are similar incentives to create spectator excitement and tension, and raise public interest. Without uncertainty of outcome to which classification can be a means, betting would not make much sense and entertainment values would be reduced. ${ }^{38}$

A second rationale is found in views of sporting ideal values. Sport is performance-driven in meritocratic ways. Inequalities in biomotor capabilities and technical and tactical skills are outcomes of athletes' hard training, efforts, ambition and resilience. According to Coubertin's Olympic philosophy and the so-called 'fundamental principles' of the Olympic Movement, sport offers '... a way of life based on the joy of effort'. ${ }^{39}$ Sporting games typically reflect values of modernity and the societies in which they found their form: individualism, the value of hard work and belief in quantifiable progress and performance. ${ }^{40}$

Historical and sociocultural explanations however do not constitute a moral justification. Are there moral reasons to accept FEO? Typically, a deontological rationale is given with references to (neo)-Kantian conceptions of persons as autonomous moral agents entitled to respect and to be treated in fair and just ways. Sound classification schemes constitute a level playing field in which performances can be seen as unique expressions of athletes' talents and the efforts of developing them, and, with that, unique expressions of who they are. Murray says:

I believe that at the heart of what we care about in sport is the combination of natural talents, the dedication and discipline to perfect those talents, and the courage to test yourself against an external standard, be it a competitor, a measure of distance or height, or the clock. ${ }^{41}$

At its best, sport can be a particular, embodied instantiation of human excellence. It is in this sense, the argument goes, that sport has moral relevance and potential.

This does not mean that existing classification regimes are adequate. Classification when it comes to age, sex, body size and ability/disability is no exact science but matters of imperfect procedural justice. As the Semenya case illustrates, the binary distinction of men's and women's classes does not in any way reflect the complexity of biological sex characteristics. Indeed, sometimes procedures that can be made less imperfect with simple means. Following the FEO norm, several sports could reconsider their practice. Provided men and women are given equal opportunities, there should be no sex classification in sports such as sailing or shooting where biological sex does not exert significant and systematic impact. And, for the same reason that there are body weight classes in weight lifting and combat sports, there could be height classes in sports such as high jumping, basketball and volleyball.

Discussions of changes such as these do not come easy. Sporting systems tend to be conservative, in particular when it comes to changes in core rules. Sometimes, however, situations occur in which fairness and justice are challenged in fundamental ways and new rulings seem unavoidable. Let me return to the case of Caster Semenya.

\section{THE SEMENYA CASE REVISITED}

Classification relates to both normative and factual premises. A core normative premise is the FEO norm discussed above. Sound application of FEO depends on factual evidence. Is hyperandrogenism, or more specifically a condition in athletes with the so-called 46 XY DSD condition and with testosterone levels above $5 \mathrm{nmol} / \mathrm{L}$ who experience a material androgenising effect, ${ }^{42}$ a condition on which athletes exert little or no control and influence? As these are 'natural', inborn conditions (in a similar way as biological sex and predispositions for body size) the answer is in the affirmative. The further factual question is whether such hyperandrogonism exerts significant and systematic impact on middle distance running performance. Are the specified testosterone levels as compared with women's statistical average of such a kind that athletes within the defined group have an unfair advantage?

Experts disagree. In a review article, Ferguson-Smith and Bavington argue that hyperandrogenism is not associated with performance advantage in female athletes. ${ }^{43}$ Analysing and comparing results from women's middle distance track running, Betancurt et al argue that testosterone levels and hyperandogenism account for between $1.24 \%$ to $1.49 \%$ performance enhancement which is too low to justify ineligibility. ${ }^{44}$ Sönksen et al point to that studies referred to by the IAAF have a crosssectional design and cannot demonstrate causal relationships between testosterone levels and performance. ${ }^{45}$ Moreover, examining potential correlations did not provide statistically significant results. With a particular focus on the study by Bermon and Garnier, Pielke et al launch harsh critique of the way results are interpreted and used in the Semenya case. ${ }^{46} 47$

Still, as of June 2019, and after careful reviewing expert evidence, two out of three CAS judges accepted scientific evidence submitted by IAAF. With reference to physiological and endocrinology expertise, and with further specification and narrowing down of the 2011 Hyperandrogenism Regulations, the judges described endogenous testosterone as '...the primary driver of the difference in sports performance between males and females'. ${ }^{48}$ There is similar expert support for the IAAF proposed testosterone threshold of $5 \mathrm{nmol} / \mathrm{L}$. ${ }^{49}$ Hence, in line with FEO and with the IAAF aim of protecting the integrity of the women's class, CAS ruled in favour of IAAF's DSD Regulations.

Even if the IAAF evidence holds water, however, this decision has been exposed to two other lines of critique. One line points to IAAF's DSD policy as being based on a slippery slope argument, the other on the policy as a violation of privacy and human rights.

The slippery slope critique refers to the fact that testosterone levels are but one element in a complex neuroendocrine feedback 
system involved in human performance. ${ }^{50}$ Athletic performances are immensely complex human phenotypes. ${ }^{51}$ Moreover, each individual athlete's performance is a unique expression of that particular individual. Different individuals respond differently to identical environmental impact, for instance to identical amounts of testosterone. Following FEO, the question is what other parts of 'inborn' human variability, such as anthropometric inequalities, muscle fibre composition or the adaptability of the cardiovascular system, should be eliminated or compensated for. Selecting inequality in testosterone levels as a basis for classification and excluding other and similar inequalities seem hard to justify.

There are at least two ways of facing the slippery slope critique. First, FEO in sport is based on a modified luck egalitarian principle. Dworkin's distinction between brute and option luck can be of help. Dworkin writes:

Option luck is a matter of how deliberate and calculated gambles turn out-whether someone gains or loses through accepting an isolated risk he or she should have anticipated and might have declined. Brute luck is a matter of how risks fall out that are not in that sense deliberate gambles. ${ }^{52}$

There is a parallel here with my distinction between stable (brute) genetic outcomes, and dynamic (and to a certain extent optional) outcomes caused by developing genetic predispositions with training and hard efforts. High testosterone levels in athletes falling under the DSD Regulations are stable outcomes of brute luck. If exerting significant and systematic impact on performance, high levels can justify classification, and hence also ineligibility. Sport is neither purely luck egalitarian nor a pure meritocratic practice, but rather a test of how individuals are able to cope with and develop the dynamic genetic predispositions they are given in life. ${ }^{\text {ix }}$

The other response to the slippery slope critique is linked to the fact that classification is based on more than endocrinological variables. As among others Behrensen and Coggen et al emphasise, challenges like the ones leading to the DSD Regulations do not mean that we have to abandon sex classification. ${ }^{5657}$ Categories such as 'women' and 'men' are broad and encapsulate a series of physiological characteristics together with inequalities in socialisation and gender identity. The point with hyperandrogenism in the DSD case is that the targeted athletes are born and raised with predispositions for high testosterone levels as constitutive parts of their development. As compared with competitors within the average female testosterone range, during their adolescent and adult career they have had the potential of being stronger, faster and more enduring. To a larger degree than for instance distribution of fast and slow twitch muscle fibres, or adaptability of the cardiovascular system, elevated testosterone levels work systemically and define of who they are as persons. The argument for ineligibility in the women's class of athletes with the specified DSD condition is consistent with the argument of a men's and a women's class.

The second line of critique, summarised by Karkazis and Carpenter, considers the DSD Regulations as unjustifiable discrimination in terms of violating the dignity and privacy of affected athletes, and as a violation of rights. ${ }^{58}$ Teetzel sees the regulations as based on heteronormative standards of masculinity with destructive potential. If they want to compete,

${ }^{\text {ix }}$ For a discussion of the possibility and role of individual merit in sport, see Carr, Simon and Loland. ${ }^{53-55}$ affected athletes would have to lower their testosterone levels with medication. ${ }^{59}$ This, the argument goes, is a degradation of persons who identify and live as women and who have the right to have their legal sex and gender identity respected. Reactions to the DSD rule in the medical community originate from similar perspectives. Over time, testosterone-reducing therapies can harm athletes both physically and psychologically. ${ }^{60}$ The World Medical Association urges physicians not to take part in any treatment of reducing endogenous testosterone levels if the condition is not considered pathological. ${ }^{61}$

The response by IAAF, accepted by CAS, is that this is not just a matter of the rights of DSD athletes but also of the rights of women within statistically normal testosterone ranges to compete under fair conditions. IAAF refers to their obligation of protecting the integrity of women's sport. As CAS emphasises, the Semenya case is a typical dilemma of rights. ${ }^{\mathrm{x}}$ Does Semenya's right to compete as a female middle distance-runner outweigh the right of non-hyperandrogenetic women to be able to compete in an FEO setting?

A dilemma is per definition a difficult choice. There is no ideal solution without costs. Semenya challenges core fairness norms in sport. After having reviewed the IAAF and in particular the CAS arguments, and after the discussion of the rationale of classification schemes in sport, CAS' decision in the Semenya case and IAAF's DSD Regulations seem to be the lesser evil approach.

\section{CONCLUDING COMMENTS}

The debate over Semenya is intense and polarising to a certain extent. What seems to be lacking is further analysis of the nature of athlete classification and the normative structure of sport. Based on FEO and a distinction between stable and dynamic inequalities between athletes, I have articulated a rationale for classification schemes and attempted to illuminate not only the Semenya case but the DSD Regulations and classification issues in general.

Summing up, and if testosterone can be considered a core driver of performance in middle distance running, the FEO norm justifies restricting the women's class to runners below a certain testosterone level. Tentatively, the CAS' ruling on the eligibility of Semenya and IAAF's DSD Regulations can be justified as the lesser of evils.

There is however need for some additional comments. From an ethical point of view, it is challenging to support a policy implying that, to be included, some athletes are required to what can be labelled 'reversed doping': lowering naturally high testosterone levels with androgen suppressive therapies. Hormonal treatment has systemic and psychosomatic effects and influences

\footnotetext{
${ }^{\mathrm{x}}$ As indicated at the end of the summary of their ruling, the CAS panel must have found their decision a difficult one. Below follows a quote from the ruling ${ }^{62}$ : The Panel's expression of gratitude to Ms. Semenya. 27. In its Award, the Panel expressly pays tribute to Ms. Semenya's grace and fortitude throughout this process. The Panel expresses its profound gratitude for her dignified personal participation and the exemplary manner in which she has conducted herself throughout the proceedings. The Panel also stresses that while much of the argument in this proceeding has centred around the 'fairness' of permitting Ms. Semenya to compete against other female athletes, there can be no suggestion that Ms. Semenya (or any other female athletes in the same position as Ms. Semenya) has done anything wrong. This is not a case about cheating or wrongdoing of any sort. Ms. Semenya is not accused of breaching any rule. Her participation and success in elite female athletics are entirely beyond reproach and she has done nothing whatsoever to warrant any personal criticism.
} 
who athletes are; it challenges them as persons. Hence, my support of the DSD Regulations is conditional as there should be ways of solving the classification dilemma without such drastic measures. Are there such ways?

The regulations concern only restricted events: women's running races from $400 \mathrm{~m}$ to one English mile. The affected athletes are eligible for events that are not defined as international, in international events other than restricted events, in the men's class, or in applicable intersex or similar classifications that might be offered. ${ }^{63}$ Still, as Karkazis and Carpenter argue, all these options violate individual privacy as they imply identification of participating athletes as having an intersex variation. ${ }^{64}$ In many social and cultural settings, stigmatisation and discrimination may follow.

Other options have been suggested. ${ }^{65}$ Further insights into the mechanisms of athletic performance may enable development of algorithms that estimate more precisely enhancement effects of heightened testosterone levels and open for fine-grained classification. This does not solve the privacy challenge, though, and may also lead to endless discussions of what count as relevant and non-relevant inequalities. An alternative could be some kind of algorithmically based external handicapping system, for instance with additions in time or by modifications of the track. The handicapping option, however, seems even more vulnerable to privacy concerns. Athletes would not only be classified within a certain testosterone range but identified with individual testosterone levels and relative differences.

A third option and perhaps the only viable solution to the DSD athlete challenge is reducing the significance of binary sex classification as a whole. As a sport, athletics represents variations over basic human movement patterns: the stride, the jump and the throw. Athletics requires little infrastructure; it is inclusive and offers value of many kinds to athletes and spectators all over the world. Its current elite form however may change. With challenges such as that of classification, and being vulnerable to doping in terms of relatively strong effect of performance-enhancing drugs, sports emphasising individual testosterone-driven inequalities in biomotor capabilities may lose significance.$^{66}$ Future sport paradigms may emphasise to a larger extent technical and tactical skills together with expressive and aesthetic values where sex classification has no strong justification. Current examples include sports in creative interaction with nature such as surfing, snowboarding and climbing, or precision sports such as shooting and archery. It remains to be seen whether, and possibly how, current challenges to the binary classification scheme of women and men will change sport in the time to come.

Acknowledgements The author is grateful to two anonymous reviewers for their helpful comments.

Contributors I am the sole author of the article.

Funding The authors have not declared a specific grant for this research from any funding agency in the public, commercial or not-for-profit sectors.

\section{Competing interests None declared.}

Patient consent for publication Not required.

Provenance and peer review Not commissioned; externally peer reviewed.

Data availability statement There are no data in this work.

\section{REFERENCES}

1 Camporesi $\mathrm{S}$. When does an advantage become unfair? empirical and normative concerns in semenya's case. J Med Ethics 2019;45(11):700-4.

2 Levy A. Either/Or: sports, sex, and the case of Caster Semenya. New Yorker 2009;1:46-59.
3 For full text of the ruling, see. Available: https://www.tas-cas.org/fileadmin/user_ upload/CAS_Executive_Summary_5794_.pdf https://www.tas-cas.org/fileadmin/ user_upload/CAS_Award_-_redacted_-_Semenya_ASA_IAAF.pdf [Accessed 14 Feb 2020].

4 IAAF introduces new eligibility regulations for female classification. Available: https:// www.iaaf.org/news/press-release/eligibility-regulations-for-female-classifica [Accessed 14 Feb 2020].

5 Book of Rules. Available: https://www.worldathletics.org/about-iaaf/documents/bookof-rules [Accessed 13 Feb 2020].

6 Tribunal Arbitral du Sport / Court of Arbitration for Sport. Available: https://www.tascas.org/fileadmin/user_upload/CAS_Award_-_redacted_-_Semenya_ASA_IAAF.pdf [Accessed 14 Feb 2020].

7 Tribunal Arbitral du Sport. Available: https://www.tas-cas.org/fileadmin/user_upload/ CAS_Award_-_redacted_-_Semenya_ASA_IAAF.pdf [Accessed 14 Feb 2020].

8 Tribunal Federal. Available: https://www.bger.ch/files/live/sites/bger/files/pdf/de/4A 248_2019_yyyy_mm_dd_T_d_09_54_10.pdf [Accessed 5 Aug 2019].

9 Hirschberg AL. Hyperandrogenism in female athletes. J Clin Endocrinol Metab 2019;104(2):503-5.

10 Handelsman DJ, Hirschberg AL, Bermon S. Circulating testosterone as the hormonal basis of sex differences in athletic performance. Endocr Rev 2018;39(5):803-29.

11 Camporesi S. Ethics of regulating competition for women with hyperandrogenism. Clin Sports Med 2016;35(2):293-301.

12 Karkazis K, Carpenter M. Impossible "Choices": The Inherent Harms of Regulating Women's Testosterone in Sport. J Bioeth Inq 2018;15(4):579-87.

13 Camporesi S. When does an advantage become unfair? empirical and normative concerns in Semenya's case. J Med Ethics 2019;45(11):700-4.

14 Am J Bioeth 2012;12.

15 Section V.A. Available: https://www.tas-cas.org/fileadmin/user_upload/CAS_Award_redacted_-_Semenya_ASA_IAAF.pdf [Accessed 14 Feb 2020].

16 Behrensen $M$. In the halfway house of ill repute. Sport, Ethics, and Philosophy 2013:7(4):450-66.

17 Gleaves J, Lehrbach T, et al. Beyond Fairness: the ethics of inclusion for transgender and intersex athletes. J Philos Sport 2016:43(2):311-26.

18 Murray TH. Good sport. Why our games matter - and how doping undermines them. New York: Oxford University Press, 2018: 87-106.

19 . Available: https://resources.fifa.com/mm/document/footballdevelopment/generic/02/ 86/63/17/fifa_youthfootball_e_neutral.pdf [Accessed 14 Feb 2020].

20 . Available: https://www.sailing.org/tools/documents/2019Classificati onCode-[24778].pdf [Accessed 14 Feb 2020].

21 Sullivan CF. Gender verification and gender policies in elite sport. Eligibility and 'fair play'. Journal of Sport and Social Issues 2011;35(4):400-19.

22 Karkazis K, Jordan-Young R, Davis G, et al. Out of bounds? A critique of the new policies on hyperandrogenism in elite female athletes. Am J Bioeth 2012;12(7):3-16.

23 IOC consensus meeting on sex reassignment and hyperandrogenism November 2015. Available: https://stillmed.olympic.org/Documents/Commissions_PDFfiles/ Medical_commission/2015-11_ioc_consensus_meeting_on_sex_reassignment_and hyperandrogenism-en.pdf [Accessed 14 Feb 2020].

24 Betancourt JO, Zakynthinak MS, Martinez-Patino MJ, et al. Hyperandrogenic athletes: performance differences in elite-standard 200 meter and 800 meter finals. J Sport Sci 2018;38(21):2464-71.

25 Grespan CL, Goellner VS. Fallon Fox: a Queer body in the Octagon. Movimento 2014;20(4):1265-82

26 Fouché R. Game changer. The Techno-Scientific revolution in sports. Baltimore: Johns Hopkins University Press, 2017: 100-28.

27 Loland S. Fair play in sport. A moral norm system. London: Routledge, 2002: 41-105.

28 Suits B. The elements of sport. In: Osterhoudt R, ed. The philosophy of sports. A collection of essays. Springfield III: Charles C Thomas, 1973: 46-64.

29 Tweedy SM, Vanlandewijck YC. International Paralympic Committee position standbackground and scientific principles of classification in Paralympic sport. Br J Sports Med 2011:45(4):259-69.

30 Sullivan CF. Op. CIT. 2011.

31 Coe reiterates reasons for new eligibility regulations for female classifications (DSD) in meeting with athletics South Africa president. Available: https://www.iaaf.org/news/ press-release/dsd-regulations-meeting-south-africa [Accessed 14 Feb 2020].

32 Arneson R. Equality of opportunity. In: Zalta EN, ed. The Stanford encyclopedia of philosophy. Summer 2015 ed, 2015. https://plato.stanford.edu/archives/sum2015/ entries/equal-opportunity/ [Accessed 5 Aug 2019].

33 Elster J. Local justice. How institutions allocate scarce goods and necessary burdens. New York: Sage, 1992.

34 Rawls JA. A theory of justice. Cambridge, Mass: Harvard University Press, 1999: 57-64.

35 Anderson ES. What is the point of equality? Ethics 1999;109(2):287-337.

36 Arneson. op. cit.: chapter 72015.

37 Elias N, Dunning E. The quest for excitement: Sport and leisure in the civilizing process. London: Wiley-Blackwell, 1986.

38 Frey JH. Social risk and the meaning of sport. Socio/ Sport J 1991;8(2):136-45.

39 Olympic Charter. Available: https://stillmed.olympic.org/media/Document\%20Library/ OlympicOrg/Olympic-Studies-Centre/List-of-Resources/Official-Publications/OlympicCharters/2015-Olympic-Charter.pdf\#_ga=2.217343446.1902901254.1570551687285292836.1570551687 [Accessed 14 Feb 2020].

40 Guttmann A. From ritual to record. The nature of modern sport. New York: Columbia University Press, 1978. 
41 Murray. op. cit::21, 2018

42 IAAF's Eligibility Regulations for the Female Classification, Clause 2.2. Available: https:// www.worldathletics.org/about-iaaf/documents/book-of-rules [Accessed 13 Feb 2020].

43 Ferguson-Smith MA, Bavington LD. Natural selection for genetic variants in sport: the role of $Y$ chromosome genes in elite female athletes with 46,XY DSD. Sports Med 2014;44(12):1629-34.

44 Fornet-Betancourt Ret al. Op. CIT 2018.

45 Sőnksen PH, Bavington LD, Boehning T, et al. Hyperandrogenism controversy in elite women's sport: an examination and critique of recent evidence. Br J Sports Med 2018;52(23):1481-2.

46 Bermon S, Garnier P-Y. Serum androgen levels and their relation to performance in track and field: mass spectrometry results from 2127 observations in male and female elite athletes. Br J Sports Med 2017;51(17):1309-14.

47 Pielke R, Tucker R, Boye E. Scientific integrity and the IAAF testosterone regulations. Int Sports Law J 2019:19(1-2):18-26.

48 Tribunal Arbitral du Sport / Court of Arbitration for Sport. Available: https://www.tascas.org/fileadmin/user_upload/CAS_Executive_Summary_5794_.pdf, p. 5. Accessed February 14, 2020. See also Section I in CAS' ruling of April 30, 2019: https://www. tas-cas.org/fileadmin/user_upload/CAS_Award_-_redacted_-_Semenya_ASA_IAAF. pdf [Accessed 14 Feb 2020].

49 Handelsman DJ. Op. CIT 2018

50 Hirschberg. Op. CIT 2019.

51 Pitsiladis Y, Wang G, Wolfarth B, et al. Genomics of elite sporting performance: what little we know and necessary advances. Br J Sports Med 2013;47(9):550-5.

52 Dworkin R. Sovereign virtue: the theory and practice of equality. Cambridge, MA: Harvard University Press, 2000.
53 Carr D. Where's the merit if the best man wins? J Philos Sport 1999;26(1):1-9.

54 Simon R. Deserving to be lucky: reflections on the role of luck and desert in sports. J Philos Sport 2007;34(1):13-25.

55 Loland S. Simon on luck and desert in sport: a review and some comments. J Philos Sport 2016;43(1):15-25.

56 Berehnsen. Op. CIT 2013.

57 Coggon J, Hammond N, Holm SØren. Transsexuals in Sport-Fairness and freedom, regulation and law. Sport Ethics Philos 2008;2(1):4-17.

58 See Karkazis and Carpenter. Op CIT 2018.

59 Teetzel S. The Onus of Inclusivity: Sport Policies and the Enforcement of the Women's Category in Sport. J Philos Sport 2014;41(1):113-27.

60 Jordan-Young RM, Sönksen PH, Karkazis K. Sex, health, and athletes. BMJ 2014;348(apr28 9):g2926.

61 World Medical Association. Available: https://www.wma.net/news-post/wma-urgesphysicians-not-to-implement-iaaf-rules-on-classifying-women-athletes/ [Accessed 14 Feb 2020].

62 Executive summary. Available: https://www.tas-cas.org/fileadmin/user_upload/CAS_ Executive_Summary_5794_.pdf [Accessed 14 Feb 2020].

63 IAAF's Eligibility Regulations for the Female Classification. Available: https://www. worldathletics.org/about-iaaf/documents/book-of-rules [Accessed 13 Feb 2020].

64 Karkazis and Carpenter. Op. CIT. 2018.

65 See Camporesi. op. cit. for a critical review 2019.

66 Loland S. Olympic sport and the ideal of sustainable development. J Philos Sport 2006;33(2):144-56. 